\title{
The Goldilocks Effect of Strategic \\ Human Resource Management? \\ Optimizing the Benefits of a \\ High-Performance Work System \\ Through the Dual Alignment of \\ Vertical and Horizontal Fit
}

Fit is a foundational concept in strategic human resource management (SHRM). In this context, there are two types of fit: vertical fit, which refers to the degree of alignment between a firm's HR strategy and its business strategy, and horizontal fit, or the extent to which a firm's bundle of HR activities is aligned or mutually reinforcing. The dual alignment model of SHRM postulates that organizations perform best when both types of fit are in play. This study provides support for the dual alignment model and, thus, for a comprehensive and integrative approach to the design and implementation of HR strategies.

Data for the study derive from Workplace Panel Surveys conducted biennially between 2005 and 2011 by the Korean Labor Institute. The overall sample included 1,416 firms representing 17 different industries. Data analysis involved 3,456 establishmentyear observations $-806,842,897$, and 911 across the four years covered by the study. Figure 1 below depicts the data analysis process.

\section{FIGURE 1}

Proposed Conceptual Model of This Study

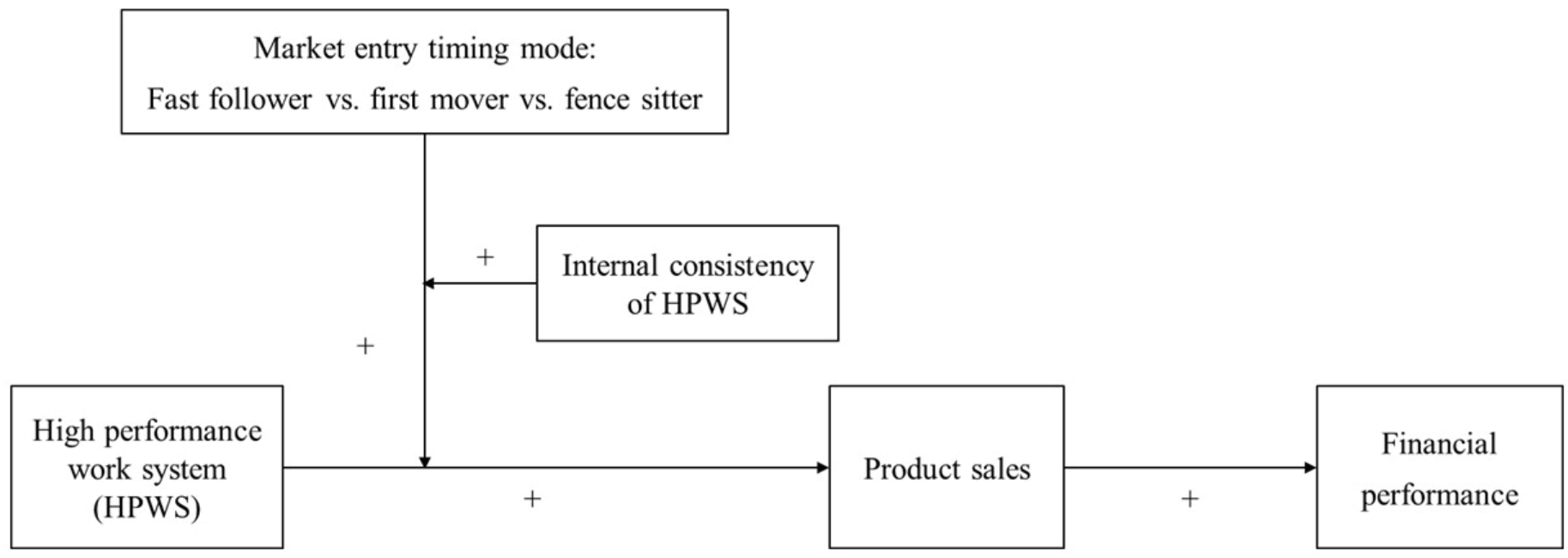

Across all firms, greater use of a generic high performance work system (HPWS), a well-known and widely studied approach to HR strategy, was associated with significantly higher sales per employee two years hence. But what about vertical fit? Did the strength of this relationship vary across firms utilizing different business strategies, in this case varying approaches to entering new markets? 


\section{FIGURE 2}

Effects of a HPWS on Subsequent Product Sales Across Market Entry Timing Modes

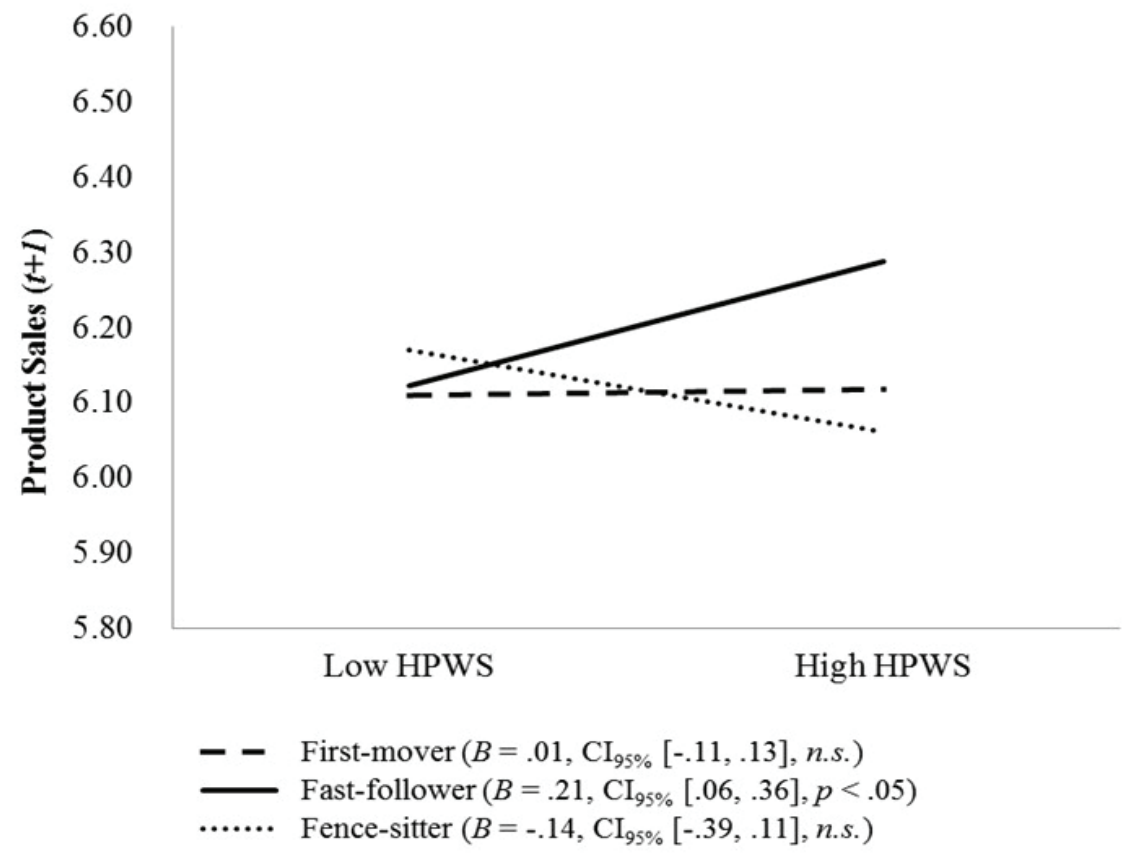

Based on a preliminary analysis, the researchers reasoned that the employee attributes engendered by a HPWS were more in line with those required to implement a fast-follower market entry strategy than those required to be either a first-mover or fence-sitter (hesitant entrant) in new marketplaces. Consistent with the concept of vertical fit, the data supported this notion of alignment; as shown in Figure 2 above, the relationship between the use of a HPWS and subsequent product sales was significantly higher among fast-followers than among firms pursuing either of the other business strategies.

Then, what about horizontal fit? Would this relationship be stronger among firms that tightly bundled their HPWSs than among those that didn't? Tightly bundled refers to the degree of internal consistency among - or equality of effort devoted to - the three major factors influenced by a HPWS: employee ability, motivation, and opportunity (AMO). Support for the dual alignment model was particularly strong. Fast-followers that had achieved vertical fit and then complemented it with horizontal fit experienced significantly higher sales increases than did either first-movers or fence-sitters which, lacking vertical fit, saw no financial benefits from investing in achieving horizontal fit (see the top half of Figure 3 on page 3). Further, none of the firms benefitted financially from HPWSs that lacked horizontal fit; that is, from investing in just one or two factors - ability, motivation, or opportunity - rather than uniformly across all three (bottom half of Figure 3 ).

The implications for human resource strategists are clear. The first, and most obvious, task is to achieve vertical fit; that is, to analyze business strategies to determine where employees can make significant contributions and then to design HPWSs in ways that produce the requisite employee abilities, motivation, and opportunities to maximize their contributions. Second, and perhaps more challenging, is the need to invest the time and resources it takes to achieve internal consistency and tight integration across the various activities inherent in a HPWS. That is, to devote time, effort, and cash in activities aimed at simultaneously enhancing employee abilities (e.g., careful selection, promotion from within, and extensive training); motivation (e.g., performance assessment, competitive and performance-based pay, and profit sharing); and opportunity (e.g., greater autonomy or control over work, encouraging employee inputs, and widespread transparency and information sharing). 


\section{FIGURE 3}

Effects of a HPWS on Subsequent Product Sales Across Market Entry Timing Modes

Under High vs. Low Degrees of HPWS Internal Consistency
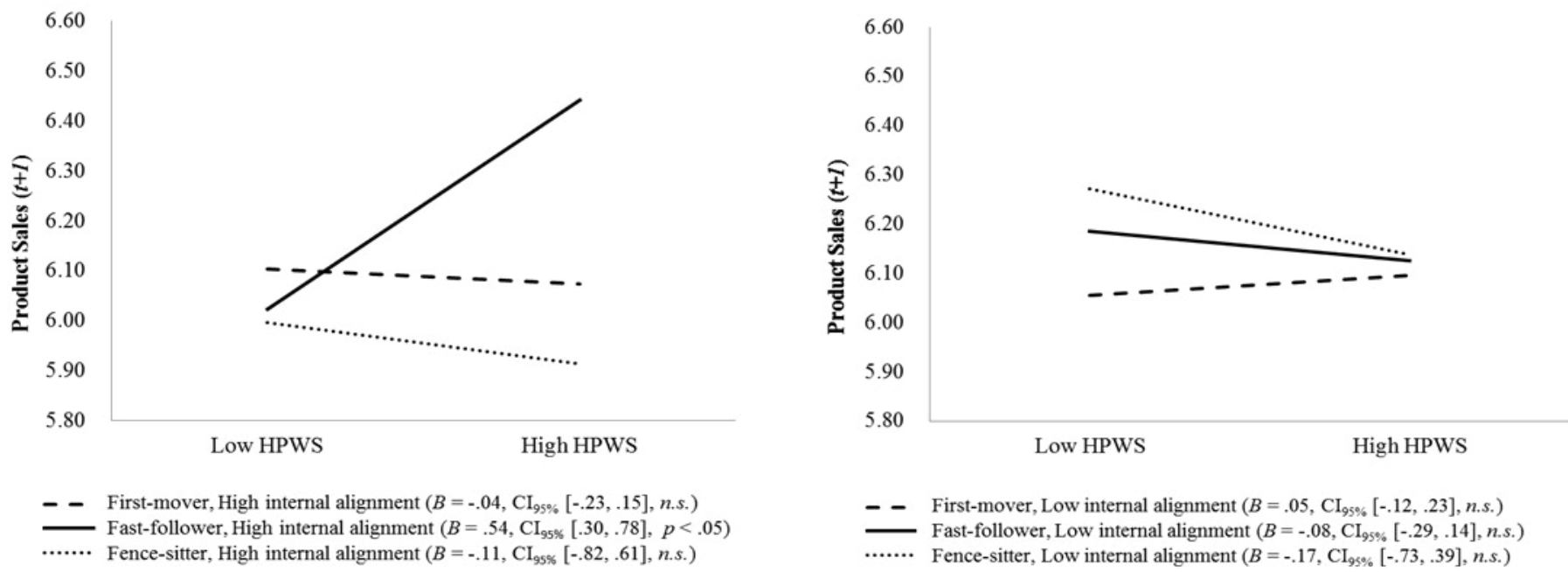

Some may balk at the costs of these investments. They needn't. The firms in this study that were one standard deviation above the industry mean in the strength of their HPWSs and also made substantial investments to achieve both vertical and horizontal fit experienced on average a nearly $23 \%$ boost in profitability over and above their peers. In other words, the costs of the investments that these leading-edge firms made were more than offset by much greater sales (and most likely lower labor costs due to higher productivity) with very favorable effects on their bottom lines.

As always, there is a need for further research. It would be helpful to replicate this study using a sample of U.S. firms. And particularly helpful to conduct studies within firms to capture the dynamics involved in the strategy-making process, as well as the flow-through of the costs and benefits involved. CAHRS actively encourages firms that are interested in these issues to contact Professor Rebecca Kehoe at the ILR School who would be happy to discuss them and, especially, to get involved in additional research aimed at improving the contributions of HR strategists and strategies.

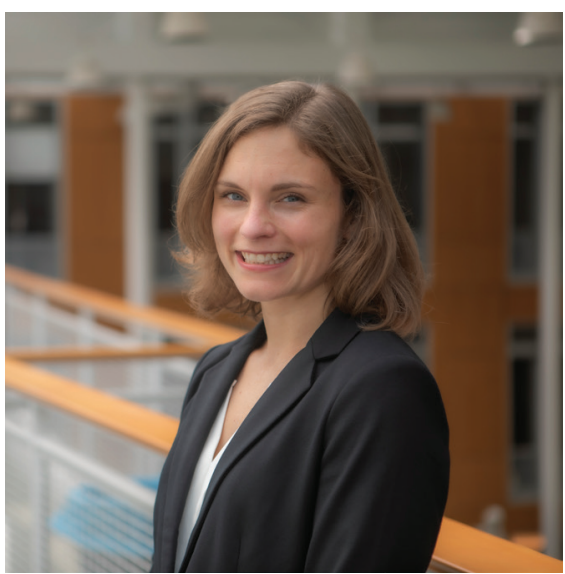

Researchers: Joo Hun Han, Rutgers, The State University of New Jersey; Saehee Kang, Marquette University; In-Sue Oh, Temple University; Rebecca R. Kehoe, Cornell University (pictured above); and David P. Lepak University of Massachusetts, Amherst.

The paper that this ResearchBrief was summarized from will be published in the October 2019 issue of the Academy of Management Journal. 